\title{
Steady State Is Not Achieved for Most Plasma Amino Acids during 12 Hours of Fasting in the Neonatal Piglet
}

\author{
ROBERT F.P. BERTOLO, JANET A. BRUNTON, PAUL B. PENCHARZ, AND RONALD O. BALL \\ Department of Agricultural, Food and Nutritional Science, University of Alberta, Edmonton, AB, Canada, \\ T6G 2P5 [R.F.P.B., J.A.B., P.B.P., R.O.B.]; Departments of Nutritional Sciences [P.B.P., R.O.B.] and \\ Paediatrics [P.B.P.], University of Toronto, Toronto, ON, Canada M5S 3E2; and The Research Institute, \\ The Hospital for Sick Children, Toronto, ON, Canada M5G 1 X8 [P.B.P., R.O.B.]
}

\begin{abstract}
ABST
Kinetics studies in neonates are important to establish the
requirement for amino acids and to understand the mechanisms
of normal and altered metabolism. During kinetics experiments,
plasma amino acid concentrations should be in steady state. Our
objective was to determine whether 12 h of fasting, after paren-
teral or enteral feeding, resulted in a steady state in concentra-
tions of amino acids. Two-day-old piglets were implanted with
catheters (d 0), and randomly assigned to either intragastric (i.g.,
$n=6$ ) or i.v. ( $n=6$ ) feeding. On d 5, piglets were fasted for
12 h. During the first 2 h, plasma concentrations of almost all
amino acids declined except asparagine (i.g. and i.v.), tyrosine
(i.v.), and glycine (i.v.), which increased. Only i.g. glycine did
not change. Between 2 and 12 h, the only indispensable amino
acids that did not change were phenylalanine (i.v.) and histidine
(i.g. and i.v.). The branched-chain amino acids increased during
\end{abstract}
The amino acid requirements for neonates have not been empirically determined, but have been extrapolated from the amino acid concentrations found in human or cow milk. This simplistic approach is inadequate when considering requirements for parenterally fed infants, premature infants, infants with disorders of amino acid metabolism, or other medical conditions that alter protein metabolism. Furthermore, a possible consequence of metabolic immaturity is that certain amino acids that are deemed dispensable in mature animals are actually indispensable, or conditionally indispensable, in the neonate.

Elucidating amino acid kinetics in an appropriate animal model is the first step to establishing requirements for neonates. An important question that must be resolved for the development of such a model is whether to study the subject in a fasted or fed state. Studies of amino acid kinetics using

Received January 27, 2000; accepted June 8, 2000

Correspondence and reprint requests: Dr. Ronald O. Ball, Department of Agricultural, Food and Nutritional Science, 4-10 Agriculture/Forestry Centre, University of Alberta, Edmonton, AB, Canada T6G 2P5.

Supported by the Natural Sciences and Engineering Research Council of Canada and Alberta Pork Producers Development Corporation. this period (i.v. and i.g.). The greatest change was tyrosine, increasing $13 \%$ (i.v.) and $32 \%$ (i.g.) per hour. After $12 \mathrm{~h}$ of refeeding, glycine, serine, threonine, and asparagine concentrations were lower than baseline $(p<0.05)$ in the i.v. group. In i.g. fed piglets, only threonine remained below baseline $(p<0.05)$, and arginine was greater than baseline $(p<0.05)$. Differences between i.v. and i.g. may be the result of impaired small intestinal metabolism secondary to parenteral feeding. In neonatal pigs, most plasma amino acids were unstable during $12 \mathrm{~h}$ of fasting. Thus, kinetics studies that require a steady state must be conducted in the fed state. (Pediatr Res 48: 701-707, 2000)

\section{Abbreviations}

BCAA, branched-chain amino acids

i.g., intragastric isotope tracers are commonly conducted in the fasted or postabsorptive state in adults (1-3) and sometimes in neonates (4). However, a prolonged fasting state may be inappropriate for neonates such as piglets and human infants, which suckle frequently, every 1 to $4 \mathrm{~h}$. However, to determine basal amino acid kinetics or to establish requirements for conditionally indispensable amino acids, the fasted state could be more informative. To conduct kinetic experiments, amino acid concentrations must be in a steady state so that isotopic steady state can be achieved during a constant infusion protocol (5). Whether the fasted state represents a quasi-steady state in the neonatal piglet, a common model for the human infant, has not been determined. The objective of this study was to determine whether amino acid concentrations reach a steady state during $12 \mathrm{~h}$ of fasting in piglets previously adapted to either i.g. or i.v. feeding.

\section{METHODS}

Animals and surgical procedures. Twelve intact, male Yorkshire piglets were obtained from a specific pathogen-free 
herd. Piglets were left with the sow for $2-4 \mathrm{~d}$ after birth, then were transferred to the laboratory for immediate surgical implantation of catheters under aseptic conditions. Anesthesia was induced with an intramuscular injection of acepromazine $(0.5 \mathrm{mg} / \mathrm{kg}$, Atravet, Ayerst Laboratories, Montreal, PQ, Canada) and ketamine hydrochloride $(10 \mathrm{mg} / \mathrm{kg}$, Rogarsetic, Rogar STB Inc., Montreal, PQ, Canada) and was maintained during surgery with a mixture of oxygen and halothane (Fluothane, Ayerst Laboratories) delivered by mask. Each piglet had a Silastic venous sampling catheter (Ed-Art, Toronto, ON, Canada) implanted, which was inserted into the left femoral vein and advanced to the inferior vena cava immediately caudal to the heart. Piglets in the i.v. fed group $(n=6)$ also received an infusion catheter, which was inserted into the left external jugular vein and advanced to the superior vena cava immediately cranial to the heart. In the i.g. fed group $(n=6)$, a Stamm gastrostomy was performed (6) to provide continuous enteral feeding.

After surgery, piglets were treated immediately with 0.15 $\mathrm{mg} / \mathrm{kg}$ oxymorphone analgesic (Numorphone, Dupont Canada Inc., Mississauga, ON, Canada) and $3.5 \mathrm{mg}$ gentamicin sulfate (Garasol, Schering Canada Inc., Pointe Claire, PQ, Canada), followed by $2.5 \mathrm{mg} / \mathrm{d}$ gentamicin sulfate for the next $3 \mathrm{~d}$. Piglets were housed in individual circular metabolic cages that allowed visual and aural contact with other piglets; toys and blankets were also provided. The room was lighted from $0800 \mathrm{~h}$ to $2000 \mathrm{~h}$ and was maintained at $28^{\circ} \mathrm{C}$ with supplemental heat provided by heat lamps. All piglets were weighed daily, and sampling catheters were flushed with sterile, heparinized saline to maintain patency. Piglets and cages were cleaned daily. All procedures were in accordance with the Canadian Council on Animal Care's Guide to the Care and Use of Animals (1993), and were approved by the local animal care committee.

Diets. An elemental and complete total nutrition diet (7) was infused continuously $(24 \mathrm{~h})$ either i.v. or i.g., via pressuresensitive peristaltic pumps, through a swivel-tether system (Alice King Chatham Medical Arts, Los Angeles, CA, U.S.A.). The infusion regimen was designed to supply all nutrients required by piglets (8). The amino acid composition of the total parenteral nutrition solution ( $\mathrm{mg} / \mathrm{g}$ total $\mathrm{L}$-amino acids) was as follows: alanine 105 , arginine 60 , aspartate 60 , cysteine 14 , glutamate 104 , glycine 31 , histidine 30 , isoleucine 45 , leucine 103 , lysine 102 , methionine 19 , phenylalanine 40 , proline 82 , serine 55 , taurine 4 , threonine 52 , tryptophan 21 , tyrosine 21 , and valine 52. Part of the tyrosine and glycine components were supplied as the soluble dipeptide, glycyl-L-tyrosine. Targeted intakes were $15 \mathrm{~g}$ amino acids $\cdot \mathrm{kg}^{-1} \cdot \mathrm{d}^{-1}$ and $1.1 \mathrm{MJ}$ metabolizable energy $\cdot \mathrm{kg}^{-1} \cdot \mathrm{d}^{-1}$ with glucose and lipid (Intralipid 20\%, Pharmacia-Upjohn, Stockholm, Sweden) each supplying $50 \%$ of nonprotein energy. All piglets were maintained on full, nutritionally complete feeding until the morning of $\mathrm{d} 5$.

Experimental design. Beginning on the morning of d 5, all piglets were fasted for $12 \mathrm{~h}$. Immediately after blood sampling for baseline data (time 0), the diet infusion was stopped. Venous blood was sampled every $2 \mathrm{~h}$ for $12 \mathrm{~h}$, during which time piglets had ad libitum access to drinking water. Diet infusion was reinitiated immediately after the blood sampling at $12 \mathrm{~h}$. To assess recovery, blood samples were obtained at $14 \mathrm{~h}$ and $24 \mathrm{~h}$ after the initiation of the fasting.

Plasma free amino acid concentrations were determined by reverse-phase HPLC. Briefly, $100 \mu \mathrm{L}$ of plasma was mixed with $20 \mu \mathrm{L}$ of $2.5 \mathrm{mM}$ norleucine (internal standard) and $1 \mathrm{~mL}$ of protein precipitant $(0.5 \%$ trifluoroacetic acid in methanol), vortexed, and centrifuged at $3000 \times g$ for $5 \mathrm{~min}$ to remove proteins. Preparation of phenylisothiocyanate derivatives for reverse-phase HPLC was then performed as previously described (9). Whole blood glucose concentration, $\mathrm{pH}$, osmolality, and sodium were determined every $2 \mathrm{~h}$ (Nova Statprofile 9+, Nova Biomedical Inc., Waltham MA, U.S.A.). Plasma urea (No. 66-UV, Sigma Chemical Co. Diagnostics, St. Louis, MO, U.S.A.) and ammonia (No. 171-UV, Sigma Chemical Co. Diagnostics) concentrations were also measured.

Statistics. Plasma amino acid concentrations throughout the fasting were retrospectively divided into acute and chronic phases (baseline to $2 \mathrm{~h}$, and 2 to $12 \mathrm{~h}$, respectively) to accommodate the marked changes that were observed immediately after cessation of the diet infusions. Significant changes in the acute phase were determined by paired $t$ test comparing the baseline and 2-h concentrations; recovery of amino acid concentrations were also compared by paired $t$ test using the baseline and 24-h concentrations. For the chronic phase, linear regression was conducted for individual pigs to determine the change in amino acid concentration per hour (slope). Slopes were used to determine whether group means were significantly different from zero (one-sample $t$ test); means of slopes were then converted to percent of baseline concentration (mean) and percent of 2-h concentration (mean). Changes in blood and plasma biochemical variables were similarly analyzed using values from baseline to $12 \mathrm{~h}$. All data are presented as mean $\pm \mathrm{SD}$.

\section{RESULTS}

There were no differences in characteristics between groups of piglets receiving i.v. or i.g. diet treatments. Piglets were $2.3 \pm 0.5 \mathrm{~d}$ of age and $1.83 \pm 0.15 \mathrm{~kg}$ body weight on the day of surgery (study d 0 ). Weight gain $(157 \pm 41 \mathrm{~g} / \mathrm{d})$, measured between $\mathrm{d} 2$ and 5, also did not differ between routes of feeding.

\section{Blood Biochemistry}

Whole blood glucose concentration declined significantly throughout the duration of the fasting in 11 of 12 pigs (Fig. 1); the overall mean rate of decrease was $0.3 \pm 0.07 \mathrm{mM} / \mathrm{h}(n=12)$. Plasma urea concentration increased significantly (in 11 of 12 pigs $)$ at a mean rate of $0.32 \pm 0.16 \mathrm{mM} / \mathrm{h}(n=12$; Fig. 1$)$; plasma urea did not change in one i.g. pig. Plasma ammonia concentration and whole blood $\mathrm{pH}$ did not change during the fasting in either i.g. or i.v. groups (data not shown). Whole blood osmolarity and sodium concentration also did not change during the time without food, indicating that dehydration was not evident. Plasma glucose and urea concentrations returned to basal values at $24 \mathrm{~h}$ (after $12 \mathrm{~h}$ of refeeding; $p>0.05$; Fig. 1). 

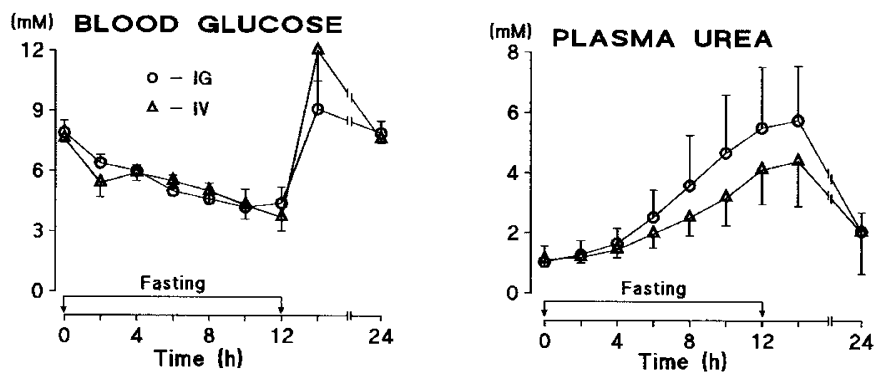

Figure 1. Whole blood glucose and plasma urea concentrations during $12 \mathrm{~h}$ of fasting. Data are mean $\pm \mathrm{SD}$. Changes in concentration during fasting are significant (i.g. and i.v.; $p<0.05$ ).
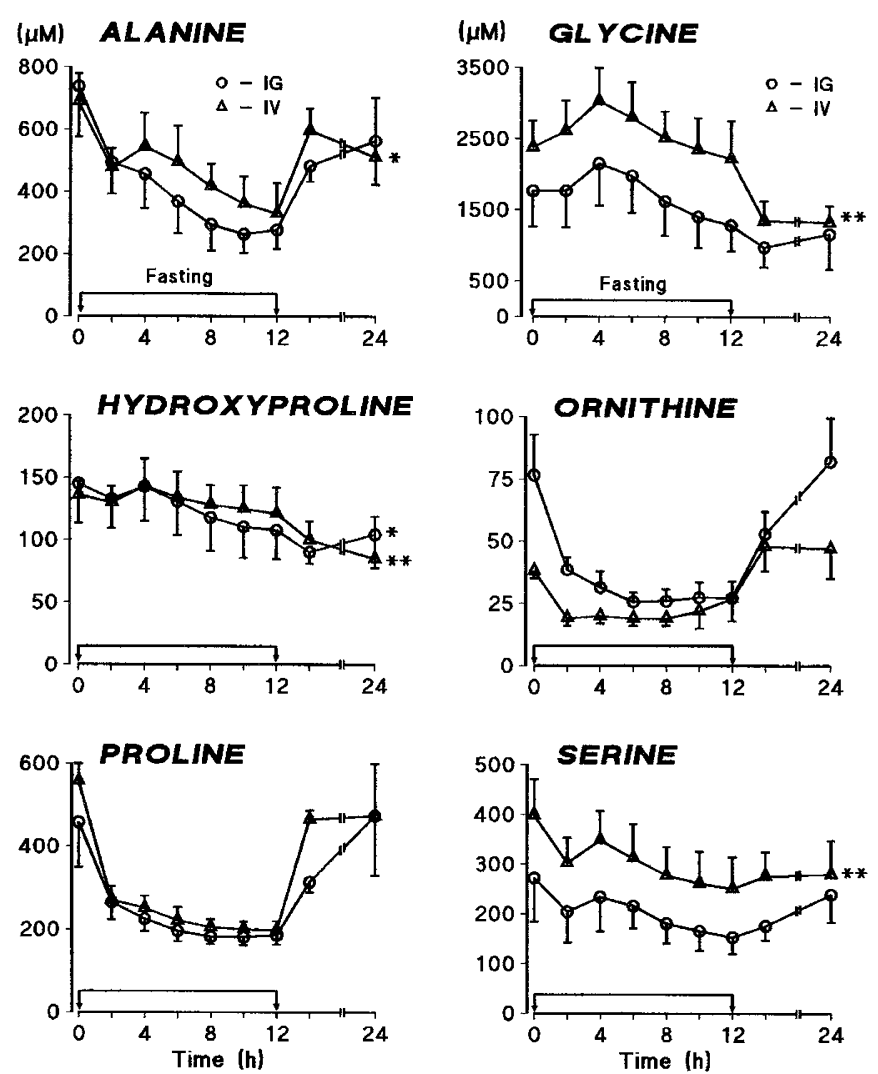

Figure 2. Plasma alanine, glycine, hydroxyproline, ornithine, proline, and serine concentrations during $12 \mathrm{~h}$ of fasting followed by continuous refeeding to $24 \mathrm{~h}$. Data are mean $\pm \mathrm{SD}$. Declines from 2 to $12 \mathrm{~h}$ are significant $(p<0.05)$ for all amino acids (i.g. and i.v.) except for i.v. ornithine and i.g. serine. Symbols indicate 24-h concentration differs from baseline $\left({ }^{* *} p<0.05 ;{ }^{*} p<\right.$ $0.10)$.

\section{Acute Responses to Fasting ( $0-2$ h)}

The initiation of fasting resulted in a marked acute decline (time 0 compared with $2 \mathrm{~h}$ ) in almost all plasma amino acid concentrations measured in both i.v. and i.g. groups (Figs. 2-6 and Table 1). Exceptions were asparagine (both i.g. and i.v.), tyrosine (i.v.), and glycine (i.v.), where concentrations significantly increased from 0 to $2 \mathrm{~h}$ (Table 1). Glycine (i.g.) and hydroxyproline (i.v.) were unchanged from 0 to $2 \mathrm{~h}$.

\section{Chronic Responses to Fasting (2-12 h)}

Amino acids that declined significantly. Continuous (2-12 h) significant decreases in plasma concentrations of 10 amino
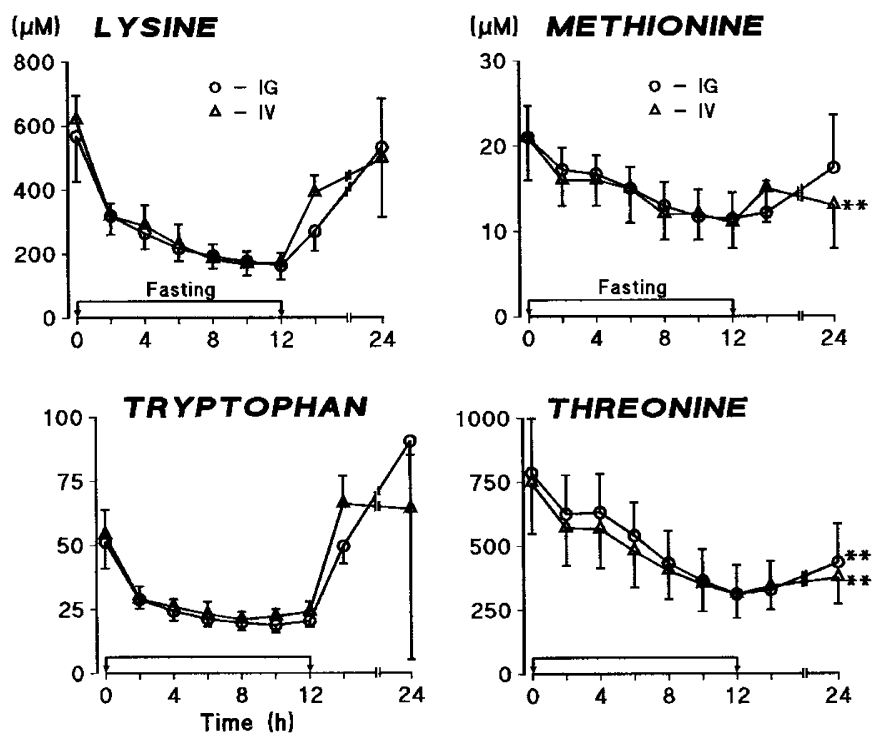

Figure 3. Plasma lysine, methionine, threonine, and tryptophan concentrations during $12 \mathrm{~h}$ of fasting followed by continuous refeeding to $24 \mathrm{~h}$. Data are mean \pm SD. Declines from 2 to $12 \mathrm{~h}$ are significant $(p<0.05)$ for all amino acids (i.g. and i.v.). Symbols indicate 24 -h concentration differs from baseline $(* * p<0.05 ; * p<0.10)$.
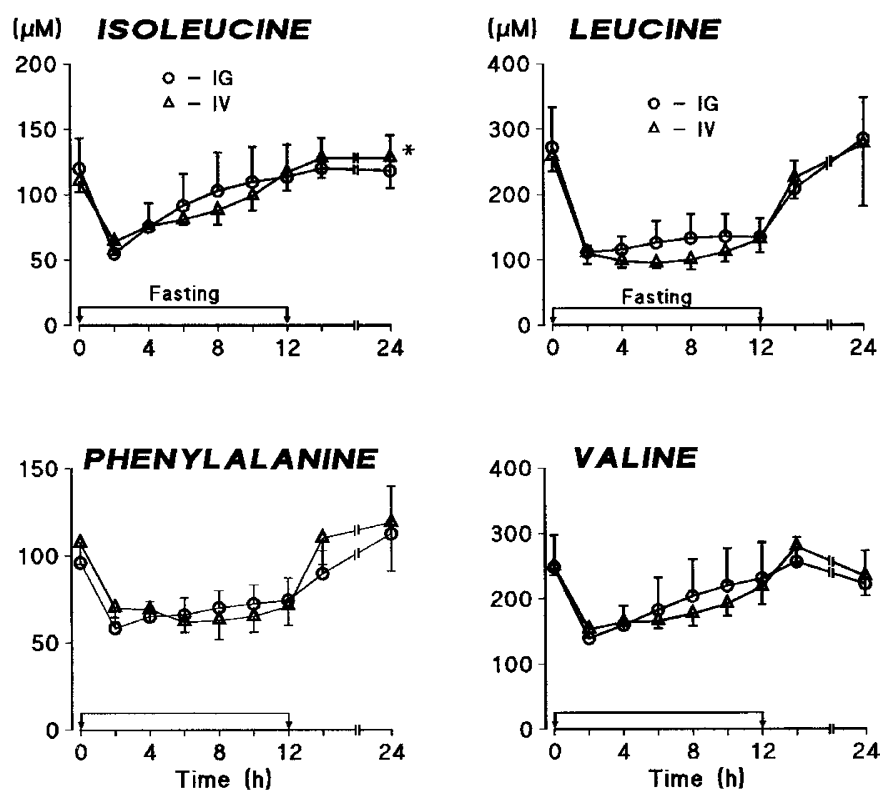

Figure 4. Plasma isoleucine, leucine, phenylalanine, and valine concentrations during $12 \mathrm{~h}$ of fasting followed by continuous refeeding to $24 \mathrm{~h}$. Data are mean $\pm \mathrm{SD}$. Increases from 2 to $12 \mathrm{~h}$ of fasting are significant $(p<0.05)$ for all amino acids (i.g. and i.v.) except for i.v. phenylalanine. Symbol indicates 24-h concentration differs from baseline $\left({ }^{*} p<0.10\right)$.

acids were observed, including alanine, glycine, hydroxyproline, ornithine, proline, and serine (Fig. 2) and lysine, methionine, threonine, and tryptophan (Fig. 3). Concentrations for all of these amino acids showed significant declines $(p<0.05)$ except for ornithine (i.v.) and serine (i.g.). The percent changes per hour were greatest for alanine, lysine, and threonine, as well as glycine (i.g. only) ( $>4 \% / \mathrm{h}$; Table 1$)$.

Amino acids that increased significantly. Increases $(p<$ 0.05 ) in plasma amino acid concentrations during the 2- to 12-h period of fasting occurred for eight amino acids, including 

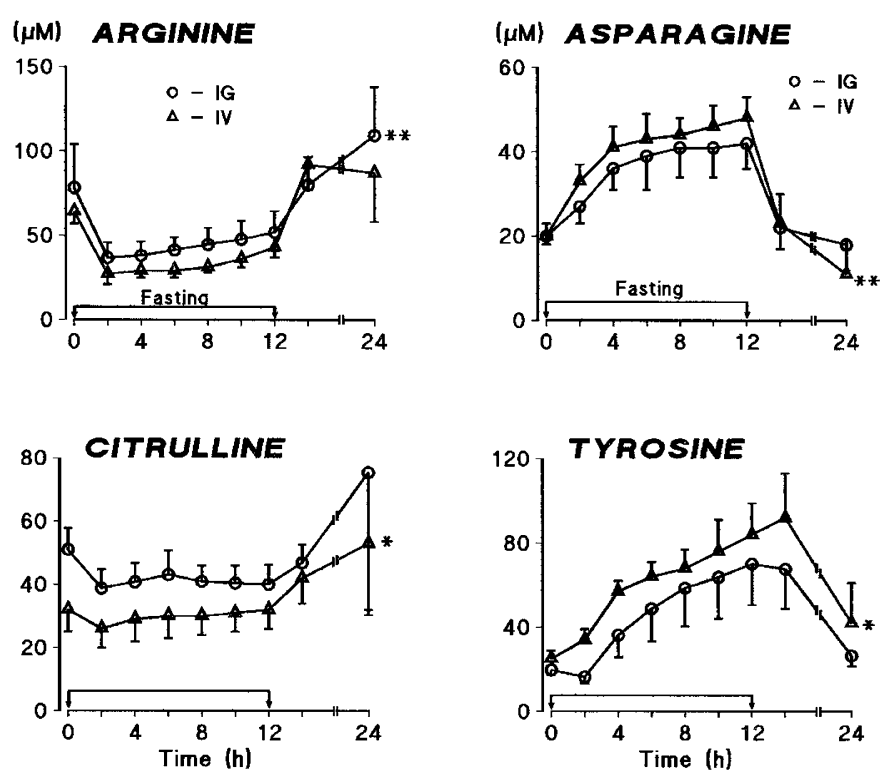

Figure 5. Plasma arginine, asparagine, citrulline, and tyrosine concentrations during $12 \mathrm{~h}$ of fasting followed by continuous refeeding to $24 \mathrm{~h}$. Data are mean $\pm \mathrm{SD}$. Increases from 2 to $12 \mathrm{~h}$ of fasting are significant $(p<0.05)$ for all amino acids (i.g. and i.v.) except for i.g. citrulline. Symbols indicate 24-h concentration differs from baseline $(* * p<0.05 ; * p<0.10)$.
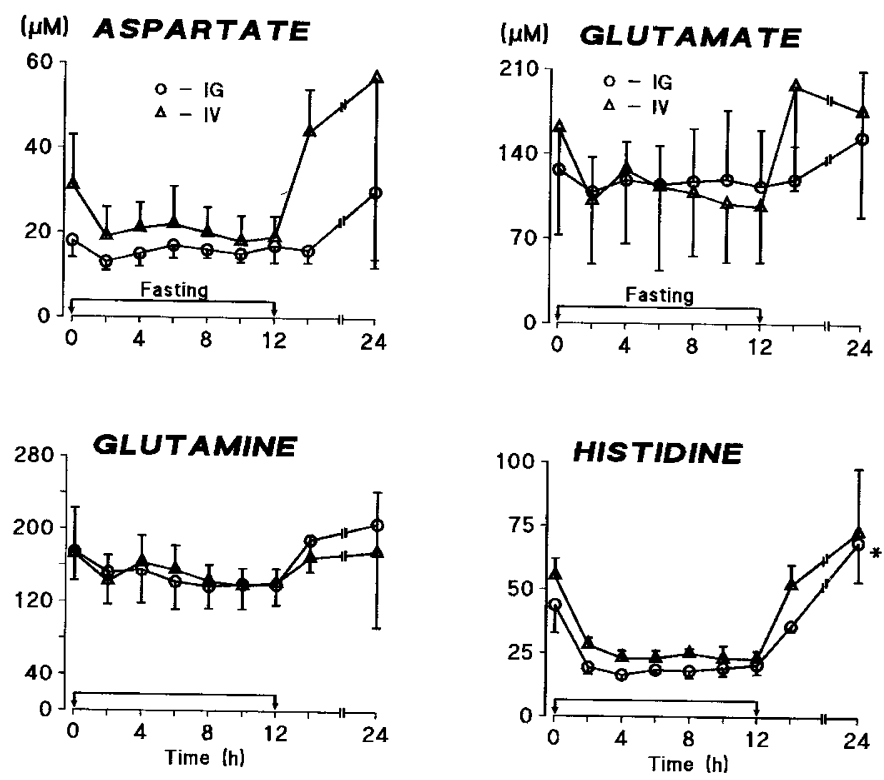

Figure 6. Plasma aspartate, glutamate, glutamine, and histidine concentrations during $12 \mathrm{~h}$ of fasting followed by continuous refeeding to $24 \mathrm{~h}$. Data are mean $\pm \mathrm{SD}$. Concentrations did not change from 2 to $12 \mathrm{~h}$ of fasting for all amino acids (i.g. and i.v.). Symbol indicates 24-h concentration differs from baseline $(* p<0.10)$.

isoleucine, leucine, phenylalanine (i.g. only), and valine (Fig. 4), as well as for arginine, asparagine, citrulline (i.v. only), and tyrosine (Fig. 5). Large percent changes per hour $(>3.8 \% / \mathrm{h})$ were observed for isoleucine, valine, arginine, and asparagine, including very large increases for tyrosine $(13 \% / \mathrm{h}$ and $32 \% / \mathrm{h}$, i.v. and i.g., respectively; Table 1).

Unchanged amino acid concentrations. Aspartate, glutamate, glutamine, and histidine concentrations were unchanged during the 2- to 12-h period of fasting in both i.g. and i.v. groups (Fig. 6). In addition, concentrations of phenylalanine (i.v. only), citrulline (i.g. only), ornithine (i.v. only), and serine (i.g. only) were also unchanged during the chronic phase of fasting.

Concentrations of several amino acids initially rose slightly $(p>0.05)$ after $2 \mathrm{~h}$ then subsequently declined, including glutamate (i.v.), glutamine (i.v.), and serine (i.g.); except for glutamate, the concentrations of these amino acids decreased significantly from 4 to $12 \mathrm{~h}(p<0.05)$.

\section{Amino Acid Concentrations After Refeeding}

After $12 \mathrm{~h}$ of refeeding, concentrations of several amino acids had not returned to baseline concentrations (Figs. 2-6). In particular, threonine concentrations did not recover in either group; in i.v. and i.g. piglets combined, the initial (time 0) plasma threonine concentration was $766 \pm 222 \mu \mathrm{M}$ and had recovered to only $405 \pm 139 \mu \mathrm{M}$ by $24 \mathrm{~h}$ ( $p<0.001$; Fig. 3 ). In i.v. piglets, concentrations of glycine (56\% of baseline), hydroxyproline $(63 \%)$, serine $(70 \%)$, methionine $(62 \%)$, and asparagine (55\%) were lower at $24 \mathrm{~h}$ compared with baseline $(p<0.05)$. In i.g. piglets, only the plasma threonine concentration was lower at $24 \mathrm{~h}$ versus baseline $(p<0.05)$. Higher concentration at $24 \mathrm{~h}$ versus baseline was observed only for arginine $(140 \%$ of baseline) in i.g. pigs $(p<0.05)$.

\section{DISCUSSION}

Experiments on amino acid kinetics in neonates have been conducted in both the fed $(10-12)$ and fasted $(4,12)$ states. Neonatal mammals suckle frequently, thus a fasting state could be considered nonphysiologic. We hypothesized that neonatal piglets would not be in a physiologic steady state during a 12-h fast because 1-wk-old piglets suckle approximately every hour. Because a steady state is necessary for primed, constant infusion experiments, we needed to verify whether or not plasma amino acid concentrations were stable during this period of food-deprivation to achieve a specific activity plateau.

We did not observe a plateau in plasma concentrations for most of the amino acids analyzed. The change with time varied from as low as $2 \% / \mathrm{h}$ up to as high as $32 \% / \mathrm{h}$, indicating that during the 12 -h fast, a steady state was not achieved. Of the 22 amino acids measured, concentrations of 10 amino acids decreased significantly, and concentrations of eight amino acids increased significantly during the 2- to 12 -h period of food deprivation in either or both groups. Plasma concentrations of only four amino acids were unchanged during food deprivation for both groups. Many factors can alter amino acid metabolism in an in vivo model, including the hormonal milieu induced by feeding or fasting, metabolic maturity of the animal, previous dietary amino acid intake, and, as we have demonstrated in this study, the route of feeding (i.e. i.v. versus i.g.). The piglet is an appropriate model for the human infant, despite differences in metabolic rates. The human infant grows at a rate that is only one-fourth that of the piglet. However, amino acid flux is also only one-fourth of the rate measured in piglets $(13,14)$. Therefore, although slower changes in plasma amino acid concentrations during fasting may be observed in infants, the relative error introduced by conducting kinetics studies in a 
Table 1. Changes in mean plasma amino acid concentrations during fasting

\begin{tabular}{|c|c|c|c|c|c|c|}
\hline \multirow[b]{2}{*}{ Amino Acid } & \multicolumn{3}{|c|}{ Intragastric } & \multicolumn{3}{|c|}{ Intravenous } \\
\hline & $\begin{array}{l}\text { Baseline } \\
(\mu \mathrm{M})\end{array}$ & $\begin{array}{c}\% \text { of baseline } \\
\text { at } 2 \mathrm{~h}^{*}\end{array}$ & $\begin{array}{c}\% \text { change } \\
\text { per h† }\end{array}$ & $\begin{array}{l}\text { Baseline } \\
(\mu \mathrm{M})\end{array}$ & $\begin{array}{c}\% \text { of baseline } \\
\text { at } 2 \mathrm{~h}^{*}\end{array}$ & $\begin{array}{c}\% \text { change } \\
\text { per h } \dagger\end{array}$ \\
\hline Histidine & $44 \pm 11$ & 43 & $\mathrm{NC}$ & $55 \pm 7$ & 51 & $\mathrm{NC}$ \\
\hline Isoleucine & $120 \pm 23$ & 46 & +10.6 & $110 \pm 8$ & 58 & +7.6 \\
\hline Leucine & $272 \pm 62$ & 40 & +2.4 & $258 \pm 22$ & 43 & +2.0 \\
\hline Lysine & $568 \pm 142$ & 56 & -4.8 & $618 \pm 77$ & 51 & -5.1 \\
\hline Phenylalanine & $96 \pm 12$ & 60 & +2.6 & $107 \pm 12$ & 65 & $\mathrm{NC}$ \\
\hline Threonine & $785 \pm 224$ & 79 & -5.7 & $746 \pm 198$ & 77 & -5.1 \\
\hline Tryptophan & $51 \pm 10$ & 57 & -3.0 & $54 \pm 10$ & 53 & -2.0 \\
\hline Valine & $248 \pm 49$ & 56 & +6.8 & $250 \pm 14$ & 61 & +3.9 \\
\hline \multicolumn{7}{|l|}{ Semi-indispensable } \\
\hline Arginine & $78 \pm 26$ & 47 & +4.2 & $64 \pm 7$ & 42 & +5.3 \\
\hline Aspartate & $18 \pm 4$ & 72 & $\mathrm{NC}$ & $31 \pm 12$ & 61 & $\mathrm{NC}$ \\
\hline Citrulline & $51 \pm 7$ & 66 & $\mathrm{NC}$ & $32 \pm 7$ & 81 & +2.0 \\
\hline Glutamate & $127 \pm 34$ & 85 & $\mathrm{NC}$ & $161 \pm 88$ & 63 & $\mathrm{NC}$ \\
\hline Glutamine & $175 \pm 32$ & 87 & $\mathrm{NC}$ & $172 \pm 51$ & 83 & $\mathrm{NC}$ \\
\hline Glycine & $1765 \pm 499$ & 100 & -4.0 & $2376 \pm 375$ & 110 & -2.3 \\
\hline Hydroxyproline & $145 \pm 32$ & 92 & -2.5 & $136 \pm 11$ & 96 & -1.2 \\
\hline Ornithine & $77 \pm 16$ & 51 & -2.5 & $38 \pm 6$ & 50 & $\mathrm{NC}$ \\
\hline Serine & $272 \pm 88$ & 75 & $\mathrm{NC}$ & $398 \pm 72$ & 76 & -2.6 \\
\hline
\end{tabular}

* Calculated as a percent of mean concentration at $2 \mathrm{~h}$ divided by mean concentration at baseline. All changes in amino acid concentrations (between 0 and $2 \mathrm{~h})$ were significant $(p<0.05)$ except glycine in the i.g. group $(p=1.0)$ and hydroxyproline in the i.v. group $(p=0.12)$.

$\dagger$ Calculated as a percent of mean concentration at $2 \mathrm{~h}$ [concentration change per hour (slope) divided by mean $2 \mathrm{~h}$ concentration]. All changes in amino acid concentrations (slopes) were significant $(p<0.05)$, unless indicated by no change (NC).

non-steady state (i.e. fasting) would be equally as large as that observed in the present study.

Of the indispensable amino acids, only plasma concentrations of histidine (i.g. and i.v.) and phenylalanine (i.v. group only) did not change significantly between 2 and $12 \mathrm{~h}$. Concentrations of the BCAA (isoleucine, leucine, and valine) all increased during the fasting in both feeding groups. Except for phenylalanine (i.g. group), concentrations of the other indispensable amino acids (lysine, methionine, threonine, and tryptophan) all decreased significantly during fasting in both groups. The plasma pool size of an indispensable amino acid is the result of influx into the pool (amino acids from diet and protein catabolism) and efflux out of the pool (amino acids to protein synthesis and oxidation). During a fast, the pool size of almost all amino acids declines rapidly in the acute phase because dietary inputs to the pools have been removed. Beyond this initial decline, net protein synthesis decreases (15-17). Thus, the contribution to the pool of free amino acids from protein catabolism increases relative to the removal of the amino acids for protein synthesis. This increase in concentration from protein catabolism is in proportion to the relative concentration of the amino acid in body proteins. For example, the BCAA are some of the most abundant amino acids in protein and yet have relatively small plasma pools (18). Therefore, a relatively large amount of free BCAA from body protein catabolism enters the small plasma pools at a rate greater than the rate leaving the pool for BCAA oxidation; indeed, the ability of the neonate to up-regulate BCAA catabolism may be limited. The net effect is that free BCAA plasma concentrations increase as the pools increase during fasting, as shown in this study. In contrast, threonine and lysine are less abundant in protein but have large plasma pools (18); thus body protein catabolism does not contribute free threonine and lysine at a rate sufficient to offset the rate of obligatory oxidation of these amino acids, resulting in a decline in plasma concentrations during a fast. During a fast, body protein breakdown is the only source of indispensable amino acid influx into the plasma pool; therefore, the change in plasma concentrations of these amino acids is related to their plasma pool sizes and relative concentration in catabolized protein.

The relationship between the rate of proteolytic release and amino acid catabolism would be more apparent from plasma amino acid concentrations near the end of the fasting period, as opposed to the beginning when dietary intake and protein synthesis may still be influencing plasma concentrations. For this reason, we conducted post hoc analyses to determine whether steady states were achieved between 6 and $12 \mathrm{~h}$ of fasting. In the i.g. group, concentrations of alanine, proline, leucine, tryptophan and ornithine were unchanging during the 6- to 12-h period, whereas in the i.v. group, citrulline, proline, methionine, tryptophan, and lysine also appeared to reach steady state during this latter period of fasting. It is important to note that concentrations of 13 of 22 amino acids during 
either route of feeding still had not achieved steady state during the latter half of a 12 -h fast.

The observed increase in BCAA concentrations is of particular importance because leucine is commonly used as a tracer to quantify protein metabolism in neonates $(19,20)$. Estimates of endogenous protein breakdown have been reported from tracer studies using leucine, phenylalanine, or both amino acids. In infants in the fed state, the ratio of the rate of appearance of endogenous phenylalanine versus leucine during simultaneous isotope infusions was different relative to the concentrations in body proteins (11). A different outcome from simultaneous phenylalanine and leucine infusions was also found in neonates receiving i.v. glucose with no amino acids. The discrepancy in kinetics between phenylalanine and leucine became greater when total parenteral nutrition was initiated in the same infants (19). Therefore, the choice of tracer, and the conditions of the study, particularly with respect to feeding, clearly influence the estimates of whole body protein metabolism.

We previously demonstrated that the threonine requirement of i.v. fed pigs is only $45 \%$ that of i.g. fed pigs (21). Thus, it was surprising that plasma threonine concentrations of i.v. piglets paralleled those of i.g. piglets before, during, and after the fast. We have previously observed similar plasma threonine concentrations between i.v. and i.g. feeding in fed piglets (22). In the fed state (i.e. before fasting), we reasoned that i.v. piglets must catabolize more threonine because although incorporation of threonine into protein is lower in i.v. fed piglets (21), plasma threonine concentrations were similar to those of i.g. fed pigs. On refeeding after the fast, one might expect to see a more rapid recovery in the group receiving the diet parenterally considering the two groups received identical threonine intakes; but this did not occur. It is possible that $12 \mathrm{~h}$ of refeeding was too short a period to detect the i.g.--i.v. differences. Alternatively, a greater rate of protein synthesis in piglets with an intact gut (i.g. pigs) may have been matched by the greater rate of threonine catabolism in i.v. piglets consuming excessive threonine. Additionally, plasma threonine concentration in either group did not recover to prefast levels after $12 \mathrm{~h}$ of refeeding, which may indicate that threonine was the first limiting amino acid. However, the threonine concentration in the diet used for refeeding was excessive relative to predetermined threonine requirements (21). Indeed, dietary threonine intake was almost 4 times the requirement for i.v. pigs, and 1.5 times the requirement for i.g. pigs. Plasma threonine concentration measured in both i.g. and i.v. piglets before fasting was approximately 2 -fold higher than that determined from sow-fed reference piglets (23), and 4-5 times higher than that in i.v. and i.g. fed piglets receiving threonine at the requirement level (21). After $12 \mathrm{~h}$ of refeeding, threonine concentrations in both groups were within the range observed in sow-fed piglets. It is possible that the high prefasting values were the cumulative effect of $5 \mathrm{~d}$ of feeding excessive threonine.

The plasma tyrosine concentrations increased dramatically during fasting, at a rate of $32 \% / \mathrm{h}$ in i.g. pigs (from $20 \pm 2 \mu \mathrm{M}$ at $2 \mathrm{~h}$ to $70 \pm 20 \mu \mathrm{M}$ at $24 \mathrm{~h}$ ) and $13 \% / \mathrm{h}$ in i.v. pigs (from $25 \pm 4 \mu \mathrm{M}$ at $2 \mathrm{~h}$ to $84 \pm 15 \mu \mathrm{M}$ at $24 \mathrm{~h}$ ). Because phenylalanine oxidation involves its hydroxylation to tyrosine as a first step, the observed increases in tyrosine concentration could be attributed to an increased rate of hydroxylation of phenylalanine or a decreased rate of tyrosine catabolism. In an analogous situation to the BCAA, the contribution of phenylalanine and tyrosine from protein breakdown is large compared with their small plasma pool sizes (18); thus, the rate of appearance of both amino acids from protein catabolism was greater than their rate of oxidation, leading to increasing plasma concentrations during the fasting.

To provide carbon units for gluconeogenesis and energy production, amino acid catabolism increases during fasting, generating large amounts of ammonia, which must be eliminated. Because plasma ammonia concentrations were unchanged during $2-12 \mathrm{~h}$ of fasting (i.v. and i.g. combined, $40.2 \pm 18.0 \mu \mathrm{M}$ ), ammonia disposal mechanisms were adequate to deal with the increased ammonia from deamination. Ammonia disposal occurs primarily via urea synthesis, and plasma urea concentrations did increase as expected (Fig. 1). Amino acids associated with ammonia transport from protein catabolism in tissues increased (asparagine), were unchanged (aspartate, glutamate, glutamine), or decreased (alanine). However, in addition to their roles as ammonia carriers, these amino acids (glutamate, glutamine, and alanine, in particular) also serve as energy sources via complete oxidation. Indeed, because of the low fat stores in these piglets, these amino acids may have served as primary fuels during a fast; this efflux from the plasma pool may have offset the increase in concentrations expected owing to increased nitrogen turnover. The dynamic roles of these nitrogen carriers combined with the instability of alanine and asparagine concentrations have significant implications for experiments using nitrogen tracers $\left(e . g .{ }^{15} \mathrm{~N}\right.$-glycine or ${ }^{15} \mathrm{~N}$-alanine) to study protein metabolism.

The response in plasma concentrations of dispensable amino acids largely depends on their roles during fasting (i.e. in ammonia disposal) as well as on their rates of de novo synthesis in the fasting state. Overall, total dispensable amino acid concentrations in this study decreased by $25 \%$ and $36 \%$ in i.v. and i.g. piglets, respectively, similar to the decline observed by Davis et al. (24) in 7-d-old piglets. Thus, even the plasma pools of the dispensable amino acids were shrinking during fasting as more and more amino acid catabolism was required to meet the needs for gluconeogenesis and energy production. For neonatal piglets, the rates of de novo synthesis or the rates of catabolism of dispensable amino acids did not reach a steady state during $12 \mathrm{~h}$ of fasting. Therefore, plasma concentrations of most amino acids were not stable enough for kinetic experimentation.

During a fast, changes in various hormones are responsible for the maintenance of fasting homeostasis in adults. However, in suckling neonates, these hormonal changes may not be developed enough to achieve a physiologic steady state in a fasting situation. In our piglets, the steady decline in blood glucose concentration throughout the fasting period indicated that glucose utilization exceeded glucose synthesis. In the adult, homeostasis is achieved in the fasting state primarily by a decrease in insulin, as well as increases in glucagon and glucocorticoid concentrations, resulting in net catabolism of protein to supply carbon for the increased rate of gluconeo- 
genesis (25). In 7-d-old piglets, both plasma insulin and IGF-I decrease significantly over a $24-\mathrm{h}$ fasting period (24). However, Wray-Cahen et al. (26) demonstrated that the sensitivity and responsiveness of whole body amino acid disposal to insulin is greater at $7 \mathrm{~d}$ than at $26 \mathrm{~d}$ of age in piglets. This developmental difference probably relates to the highly efficient use of dietary amino acids for protein deposition in neonates (27). Because the fasting state is nonphysiologic in the suckling neonate, hormonal responses may not be developed sufficiently to achieve a fasting homeostasis.

The recovery of amino acid concentrations to prefasting levels after $12 \mathrm{~h}$ of refeeding did not occur for many amino acids. After a fast, plasma insulin concentrations rebound to a greater extent in 7- than 26-d-old piglets (24), which may explain the incomplete recovery after $12 \mathrm{~h}$ of refeeding. In i.g. fed piglets in the present study, three amino acids did not recover to baseline values; threonine concentrations were lower than baseline after $12 \mathrm{~h}$ of refeeding whereas arginine and histidine $(p<0.10)$ concentrations were higher. However, in i.v. fed piglets, 11 amino acids did not reach baseline values (for five amino acids, $p<0.10$ ) with eight of the 11 having concentrations less than baseline after $12 \mathrm{~h}$ of refeeding. The difference in recovery because of route of feeding could be caused by different hormonal responses during and after fasting; however, we do not currently have any information on the differences in hormone levels in piglets because of route of feeding.

In the present study, we established that plasma amino acid concentrations are not at a steady state during a 12-h fast in piglets previously fed either i.g. or i.v. Because of this nonsteady state, the fasting condition is not appropriate for the analysis of amino acid kinetics. These findings support our hypothesis that suckling neonates are developmentally adapted to a fed state because of frequent suckling and that the fasting state represents a stressful situation to which the neonate cannot establish a physiologic steady state. Thus, any studies elucidating the kinetics of amino acids in neonates should be performed in a fed state only.

\section{REFERENCES}

1. Beaumier L, Castillo L, Ajami AM, Young V 1995 Urea cycle intermediate kinetics and nitrate excretion at normal and "therapeutic" intakes of arginine in humans. Am J Physiol 269:E884-E896

2. Castillo L, Sanchez M, Vogt J, Chapman TE, DeRojas-Walker T, Tannenbaum SR, Ajami AM, Young VR 1995 Plasma arginine, citrulline, and ornithine kinetics in adults, with observations on nitric oxide synthesis. Am J Physiol 268:E360-E367

3. Castillo L, Beaumier L, Ajami AM, Young VR 1995 Whole body nitric oxide synthesis in healthy men determined from $[15 \mathrm{~N}]$ arginine-to- $[15 \mathrm{~N}]$ citrulline labeling. Pediatr Res 37:381-388
4. Denne SC, Kalhan SC 1987 Leucine metabolism in human newborns. Am J Physiol 253: E608-E615

5. Wolfe RR 1992 Calculation of substrate kinetics: single-pool model. In: Wolfe RR (ed) Radioactive and Stable Isotope Tracers in Biomedicine: Principles and Practice of Kinetic Analysis. Wiley-Liss, Toronto, pp 119-144

6. Rombeau JL, Barot LR, Low DW, Twomey PL 1984 Feeding by tube enterostomy. In: Rombeau JL, Caldwell MD (eds) Clinical Nutrition Volume 1. Enteral and Tube Feeding. WB Saunders, Philadelphia, pp 275-285

7. Bertolo RFP, Chen CZL, Pencharz PB, Ball RO 1999 Intestinal atrophy has a greater impact on nitrogen metabolism than liver by-pass in piglets fed identical diets via gastric, central venous or portal venous routes. J Nutr 129:1045-1052

8. Wykes LJ, Ball RO, Pencharz PB 1993 Development and validation of a total parenteral nutrition model in the neonatal piglet. J Nutr 123:1248-1259

9. Bidlingmeyer BA, Cohen SA, Tarvin TL 1984 Rapid analysis of amino acids using pre-column derivatization. J Chromatogr 336:93-104

10. Darmaun D, Roig JC, Avestad N, Sager BK, Neu J 1997 Glutamine metabolism in very low birth weight infants. Pediatr Res 41:391-396

11. Van Toledo-Eppinga L, Kalhan SC, Kulik W, Jakobs C, Lafeber HN 1996 Relative kinetics of phenylalanine and leucine in low birth weight infants during nutrient administration. Pediatr Res 40:41-46

12. Denne SC, Rossi EM, Kalhan SC1991 Leucine kinetics during feeding in normal newborns. Pediatr Res 30:23-27

13. Roberts SA, Ball RO, Filler RM, Moore AM, Pencharz PB 1998 Phenylalanine and tyrosine metabolism in neonates receiving parenteral nutrition differing in pattern of amino acids. Pediatr Res 44:907-914

14. House JD, Pencharz PB, Ball RO 1997 Phenylalanine requirements determined by using $\mathrm{L}-\left[1-{ }^{14} \mathrm{C}\right]$ phenylalanine in neonatal piglets receiving total parenteral nutrition supplemented with tyrosine. Am J Clin Nutr 65:984-993

15. Burrin DG, Davis TA, Fiorotto ML, Reeds PJ 1992 Hepatic protein synthesis in suckling rats: effects of stage of development and fasting. Pediatr Res 31:247-252

16. Davis TA, Fiorotto ML, Nguyen HV, Burrin DG, Reeds PJ 1991 Response of muscle protein synthesis to fasting in suckling and weaned rats. Am J Physiol 261:R1373R1380

17. Burrin DG, Davis TA, Fiorotto ML, Reeds PJ 1991 Stage of development and fasting affect protein synthetic activity in the gastrointestinal tissues of suckling rats. J Nutr 121:1099-1108

18. Waterlow JC, Garlick PJ, Millward DJ 1978 Free amino acids. In: Waterlow JC, Garlick PJ, Millward DJ (eds) Protein Turnover in Mammalian Tissues and in the Whole Body. Elsevier/North-Holland Biomedical Press, Amsterdam, pp 117-178

19. Clark SE, Karn CA, Ahlrichs JA, Wang J, Leitch CA, Liechty EA, Denne SC 1997 Acute changes in leucine and phenylalanine kinetics produced by parenteral nutrition in premature infants. Pediatr Res 41:568-574

20. Van Goudoever JB, Sulkers EJ, Halliday D, Degenhart HJ, Carnielli VP, Wattimena JL, Sauer PJ 1995 Whole-body protein turnover in preterm appropriate for gestational age and small for gestational age infants: comparison of $[15 \mathrm{~N}]$ glycine and [1-(13)C]leucine administered simultaneously. Pediatr Res 37:381-388

21. Bertolo RFP, Chen CZL, Law G, Pencharz PB, Ball RO 1998 Threonine requirement of neonatal piglets receiving total parenteral nutrition is considerably lower than that of piglets receiving an identical diet intragastrically. J Nutr 128:1752-1759

22. Bertolo RFP, Pencharz PB, Ball RO 2000 Organ and plasma amino acid concentrations are profoundly different in piglets fed identical diets via gastric, central venous or portal venous routes. J Nutr 130:1261-1266

23. Wykes LJ, House JD, Ball RO, Pencharz PB 1994 Amino acid profile and aromatic amino acid concentration in total parenteral nutrition: effect on growth, protein metabolism and aromatic amino acid metabolism in the neonatal piglet. Clin Sci 87:75-84

24. Davis TA, Burrin DG, Fiorotto ML, Nguyen HV 1996 Protein synthesis in skeletal muscle and jejunum is more responsive to feeding in 7- than in 26-day-old pigs. Am J Physiol 270: E802-E809

25. Linder MC 1991 Nutrition and metabolism of proteins. In: Linder MC (ed) Nutritional Biochemistry and Metabolism with Clinical Applications. Elsevier Science Publishing, New York, pp 87-110

26. Wray-Cahen D, Beckett PR, Nguyen HV, Davis TA 1997 Insulin-stimulated amino acid utilization during glucose and amino acid clamps decreases with development. Am J Physiol 273:E305-E314

27. Davis TA, Fiorotto ML, Reeds PJ 1993 Amino acid compositions of body and milk protein change during the suckling period in rats. J Nutr 123:947-956 